\title{
Removal of silicone oil following diabetic vitrectomy
}

\author{
R V Pearson, D McLeod, $\star$ Z J Gregor
}

\begin{abstract}
The outcome of the removal of silicone oil from previously vitrectomised diabetic eyes was studied in a series of 25 eyes in 24 patients. Originally the patients presented with complex retinal detachments associated with proliferative diabetic retinopathy and all had reattached retinas after the initial operation. During the silicone tamponade, a number of complications had occurred. Cataract had developed in 14 eyes, glaucoma in eight, and reproliferation of fibrous membranes in 12 . After the removal of silicone the retina redetached in three eyes (in all cases associated with severe postoperative haemorrhage), hypotony occurred in five eyes (transiently in four) and the seven eyes remaining phakic developed a cataract. In spite of these problems the eventual visual acuities returned to the immediate post-vitrectomy levels in almost all the eyes.
\end{abstract}

(Brf Ophthalmol 1993; 77: 204-207)

The results of vitreous surgery for severe complications of proliferative diabetic retinopathy (PDR) have improved dramatically in recent years. ${ }^{12}$ If a retinal break is present at surgery short term intraocular gas tamponade may be effective in securing retinal re-attachment provided the break is sealed and vitreoretinal traction is adequately relieved. Occasionally, however, a prolonged tamponade using silicone oil may be preferred if the surgeon suspects that gas tamponade may not lead to lasting retinal reattachment. In eyes with chronically detached or excessively oedematous retinas, for example, it may be difficult to achieve effective endolaser photocoagulation of breaks or of ischaemic retina. In such cases silicone oil tamponade is useful as it limits any postoperative haemorrhage and allows immediate postoperative photocoagulation. ${ }^{34}$

Anterior segment complications of intraocular silicone such as cataract, glaucoma, and keratopathy $^{5-9}$ have been widely reported in nondiabetic and diabetic eyes. In addition, silicone oil in the diabetic eye may be associated with reproliferation of fibrocellular or even fibrovascular epiretinal membranes sometimes with traction retinal re-detachment. ${ }^{310}$

It is has been suggested that early removal of silicone oil may prevent some of these problems. ${ }^{11-13}$

The most serious complication of the removal of silicone is retinal re-detachment, which in non-diabetic eyes may occur in up to $33 \%$ of cases. ${ }^{14-16}$ In diabetic eyes such a complication can be particularly serious as it is frequently associated with intractable rubeosis iridis. ${ }^{17}$

It has been our clinical impression that retinal re-detachment following the removal of silicone oil is less common in diabetic eyes than in their non-diabetic counterparts. The aim of this study was to document the consequences of silicone oil removal in a series of patients who had undergone vitrectomy for complications of diabetic retinopathy.

\section{Patients and methods}

A selected series of 25 eyes in 24 patients underwent removal of silicone oil following previous vitrectomy, epiretinal membrane dissection, and fluid/silicone oil exchange for advanced PDR complicated by retinal detachment (Table 1). Thirteen patients were male and the average age was 34.2 years (range 18-59 years). Twenty two patients had insulin dependent diabetes mellitus with an average duration of 19.4 years (range 11-33 years). Two patients were non-insulin dependent with a known duration of 1 to 14 years. Sixteen of the 25 eyes had received scatter laser photocoagulation before vitrectomy and no photocoagulation had been used in nine. All eyes were phakic and five had early lens opacities.

Vitrectomy, membrane delamination, and/or segmentation and silicone oil injection $(1000 \mathrm{cS})$ was combined with endophotocoagulation in 20 eyes, cryotherapy to the post-sclerotomy retina and/or more widespread areas of peripheral retina in nine eyes, removal of subretinal membranes in two eyes, and scleral buckling in three eyes. Eyes which were not treated with extensive scatter laser photocoagulation intraoperatively received panretinal photocoagulation during the immediate postoperative period.

Complete retinal re-attachment had been achieved immediately after the initial operation in all eyes. All patients were under the care of two vitreoretinal surgeons (D McL, ZJG).

The usual indication for removal of silicone oil

Table 1 Vitreoretinal characteristics in 25 eyes before initial surgery

\begin{tabular}{ll}
\hline & Eyes \\
\hline Traction retinal detachment & 11 \\
Combined traction/rhegmatogenous retinal detachment & 14 \\
Macula detached & 23 \\
Vitreous haemorrhage & 20 \\
\hline
\end{tabular}

Table 2 Complications before silicone oil removal

\begin{tabular}{|c|c|c|}
\hline & & Eyes \\
\hline \multicolumn{3}{|l|}{ Anterior segment } \\
\hline Cataract & & 14 \\
\hline Raised intraocular pressure & & 5 \\
\hline With lens swelling & 3 & \\
\hline With rubeosis & 1 & \\
\hline With hyphaema & 1 & \\
\hline Silicone oil in anterior chamber & & 2 \\
\hline Emulsification of silicone oil & & 1 \\
\hline \multicolumn{3}{|l|}{ Posterior segment } \\
\hline Epiretinal reproliferation & & 12 \\
\hline With traction detachment & 3 & \\
\hline Without traction detachment & 9 & \\
\hline
\end{tabular}


Table 3 Indications for silicone oil removal in 25 eyes

\begin{tabular}{|c|c|}
\hline & Eyes \\
\hline $\begin{array}{l}\text { Prevention of complications } \\
\text { Cataract }\end{array}$ & $\begin{array}{r}4 \\
14\end{array}$ \\
\hline \multicolumn{2}{|l|}{ Increased intraocular pressure } \\
\hline With lens swelling & 3 \\
\hline Neovascular & 1 \\
\hline With hyphaema & 1 \\
\hline Non-resolving retrolenticular and preretinal haemorrhage & 2 \\
\hline Silicone emulsification and epiretinal reproliferation & 1 \\
\hline
\end{tabular}

Table 4 Additional procedures at silicone oil removal

\begin{tabular}{lr}
\hline Extracapsular cataract extraction and lens implant & 11 \\
Extracapsular cataract extraction without implant & 4 \\
Pars plana lensectomy & 1 \\
Intracapsular cataract extraction & 1 \\
Lensectomy/membrane dissection/scleral buckle & 1 \\
Primary posterior capsulotomy & 3 \\
Epiretinal membrane dissection & 1 \\
Trabeculectomy & 11 \\
Peripheral iridectomy & 4 \\
Intravitreal air injection & 4 \\
\hline
\end{tabular}

Table 5 Postoperative complications of silicone oil removal

Postoperative inflammation

Severe intraocular haemorrhage

Peripheral choroidal detachment

Hypotony (less than $10 \mathrm{~mm} \mathrm{Hg}$ )

Iris prolapse

Posterior capsular thickening

Cataract (in seven phakic eyes)

Retinal detachment

NB Ten eyes had multiple complications, the remaining 15 were complication free.

was either established anterior segment complications (such as cataract or glaucoma) or in an attempt to prevent such complications. In five eyes the intraocular pressure rose to a mean untreated level of $35.8 \mathrm{~mm} \mathrm{Hg}$ (range $28-50 \mathrm{~mm}$ $\mathrm{Hg}$ ). This was associated with the shallowing of the anterior chamber owing to lens swelling in three eyes, with postoperative hyphaema in one eye, and another eye developed rubeosis iridis. In two cases, the silicone oil was removed because of severe postoperative retrosilicone haemorrhage (Tables 2 and 3).

Silicone oil was removed using the technique described by Leaver et al. ${ }^{18}$ In 20 eyes this was combined with other procedures such as extracapsular cataract extraction (with or without lens implantation), lensectomy, or trabeculectomy (Table 4). Epiretinal membrane dissection with or without scleral buckling was performed at the time of the silicone oil removal in two of the eyes where epiretinal membranes had re-proliferated and a localised retinal detachment had occurred (Table 4). Mean follow up after oil removal was 50 months (6-94 months).

\section{Results}

Silicone oil was removed after having been in situ for a mean of 13.5 months (range 1-52 months). Early removal (within 3 months) was performed in order to prevent potential complications in four eyes, to treat increased intraocular pressure owing to lens swelling in four eyes, and to evacuate the retrolenticular and preretinal haemorrhage in two eyes (Table 3). A degree of diffuse haemorrhage was present in most eyes immediately following silicone removal but this cleared within 2-6 weeks. The removal of silicone oil was otherwise uneventful in 15 eyes, but was associated with complications in 10 eyes (Table 5). Four eyes had dense non-clearing haemorrhage, one of which was associated with hyphaema and high intraocular pressure requiring subsequent vitreous washout and trabeculectomy. In the remaining three eyes, the severe haemorrhage was associated with retinal re-detachment (see below).

Marked postoperative intraocular inflammation occurred in seven eyes and this was controlled by intensive topical steroids. Hypotony (intraocular pressure less than $10 \mathrm{~mm}$ $\mathrm{Hg}$ ) occurred in five eyes. This was transient (less than 10 days) in four eyes, but in one eye the intraocular pressure remained at $6 \mathrm{~mm} \mathrm{Hg}$ at 11 months. Of the five eyes with preoperative increase in intraocular pressure one underwent successful trabeculectomy at the time of silicone oil removal, but the remaining four eyes required further topical and systemic treatment in order to maintain intraocular pressure below $25 \mathrm{~mm}$ Hg.

Retinal re-detachment occurred in three eyes, in each case associated with severe postoperative intraocular haemorrhage, active fibrovascular epiretinal membrane re-proliferation, and retinal breaks. One eye was deemed inoperable and the other two were re-attached with further epiretinal membrane dissection and re-injection of silicone oil. However severe epiretinal membrane re-proliferation occurred in one of these eyes resulting in an inoperable retinal detachment. All three eyes with re-detachment following silicone oil removal presented originally with a chronic combined traction and rhegmatogenous retinal detachment and very active fibrovascular membranes.

Ultimately the retina remained attached in 23 eyes (although one contained silicone oil), 11 eyes showing some evidence of epiretinal membrane re-proliferation and three having residual extramacular traction retinal detachment that remained stable. Of the seven eyes that remained phakic after silicone oil removal, three subsequently underwent cataract extraction. Posterior capsule thickening requiring Nd-YAG capsulotomy occurred in six eyes. The remaining four phakic eyes showed posterior subcapsular opacification.

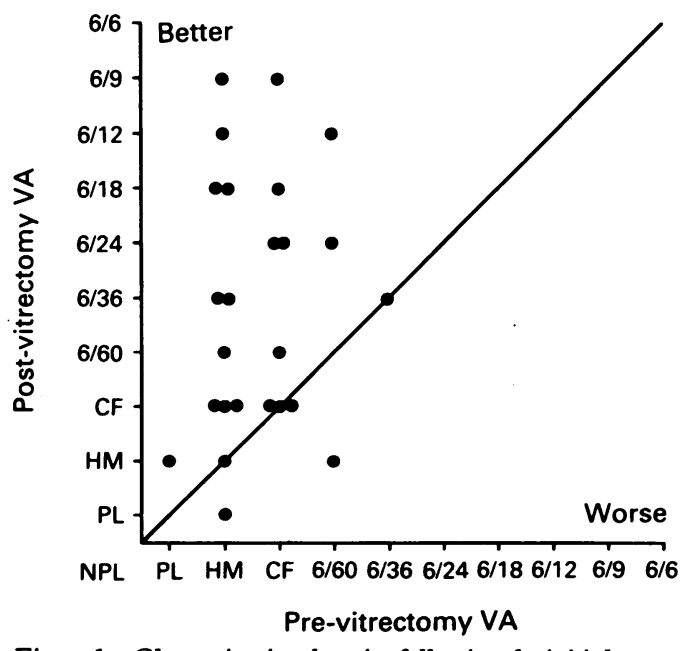

Figure 1 Change in visual acuity following the initial vitrectomy and silicone oil injection. 
Figure 2 Change in visual acuity immediately before the removal of silicone oil.

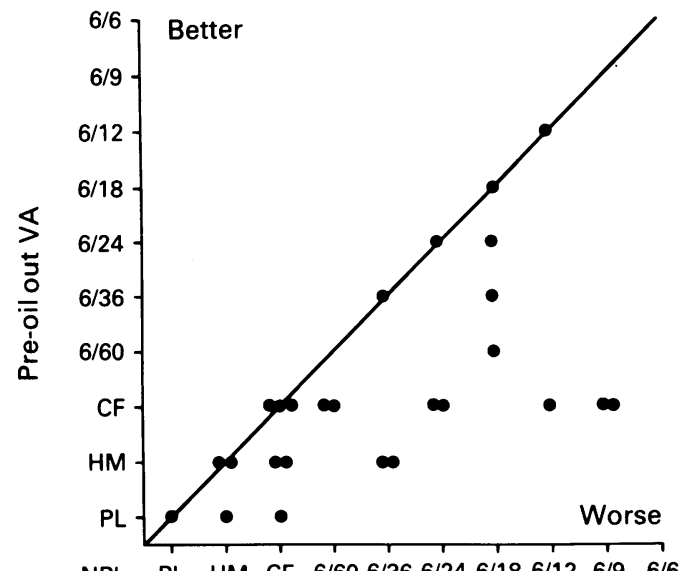

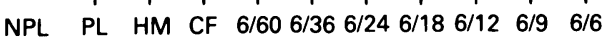

Post-vitrectomy VA

The visual acuity improved after the initial vitrectomy and silicone oil injection in $18(72 \%)$ eyes, remained unchanged in five $(20 \%)$ eyes, and deteriorated in two (8\%) eyes (Fig 1). The visual acuity decreased in $15(60 \%)$ eyes before the removal of silicone oil, usually owing to the development of cataract, but remained unchanged in 10 (40\%) (Fig 2). Following the removal of silicone oil and cataract surgery, the visual acuity improved in 19 eyes (76\%), remained the same in five $(20 \%)$, and deteriorated in one (4\%) (Fig 3).

\section{Discussion}

Silicone oil is a useful surgical tool in retinal reattachment surgery in patients with severe complications of PDR. However anterior segment complications occur in eyes with PDR just as they do in non-diabetic eyes. Cataract developed or advanced in all patients in this study either before or after the removal of silicone oil, although standard cataract surgery with or without posterior chamber implantation was successful whether at the time of silicone oil removal or at a later stage.

There was a relatively high incidence of increased intraocular pressure in the eyes studied which proved difficult to control even after the removal of silicone oil. Complications were also evident in the posterior segment both before and after the removal of silicone including epiretinal

Figure 3 Change in visual acuity following the removal of silicone. Open circles signify persistent retinal redetachment after the removal of silicone.

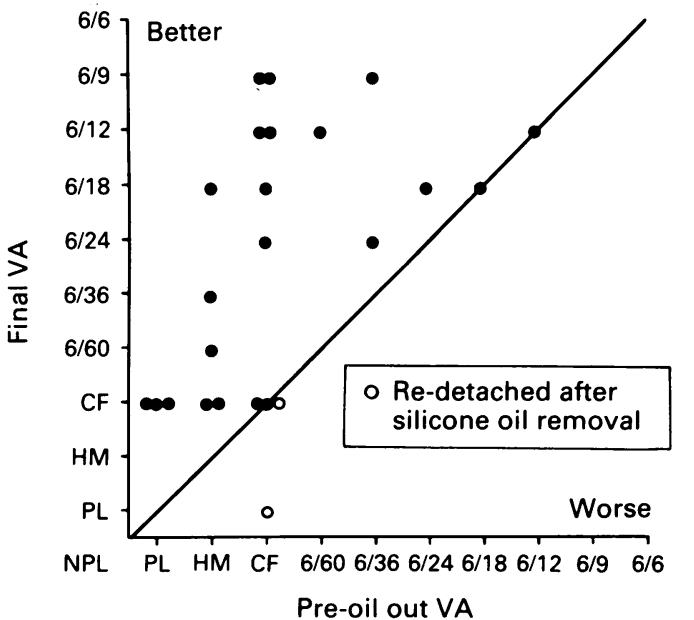

membrane re-proliferation and traction detachment. It is generally accepted that it is not possible to fill $100 \%$ of the vitreous cavity with silicone and as the silicone is buoyant, the inferior retina remains in contact with aqueous. Theoretically, growth factors become effectively 'compartmentalised' by the silicone bubble thus encouraging the re-proliferation of epiretinal membranes.

The $12 \%$ incidence of retinal re-detachment following removal of silicone oil in this study (three out of 25 eyes) is lower than that previously reported in non-diabetic eyes. ${ }^{14-16}$ This may be partly due to the relatively low number of patients in our series, but there are pathophysiological differences between diabetic and non-diabetic eyes undergoing vitrectomy. In diabetic retinopathy the proliferative process is usually confined to the post-equatorial retina and retinal breaks (pre-existing or iatrogenic) tend to be posterior and thus more easily accessible to surgical relief of any associated vitreoretinal traction. In contrast in non-diabetic eyes the retinal breaks are usually in the retinal periphery and may be difficult to close permanently, especially if anterior proliferative vitreoretinopathy is present. ${ }^{19}$ Also the extensive scatter laser photocoagulation applied to all the eyes in this series may have helped to strengthen the retinal adhesion. Interestingly two of the three retinal detachments following removal of silicone oil showed extensive pre-equatorial fibrovascular proliferation, the surgical management of which is currently one of the most challenging problems of diabetic vitrectomy. All three eyes which suffered retinal re-detachment had a severe haemorrhage in the vitreous cavity on the first postoperative day. It may be argued that such patients are poor candidates for the removal of silicone particularly since spontaneous peripheral relieving retinotomies may occur in silicone filled eyes. ${ }^{20}$

The eventual visual outcomes in this series are encouraging with most of the eyes recovering the visual acuity achieved soon after initial vitrectomy. The deterioration of vision before the removal of silicone oil was mainly due to the development of cataract, but the vision was restored once the silicone and the cataract had been removed.

1 Blankenship GW, Machemer $R$. Long term diabetic vitrectomy results. Report of a 10 year follow-up. Ophthalvitrectomy results. Report
mology 1985; 92: 503-6.

2 Rice TA, Michels RG. Long-term anatomic and functional results of vitrectomy for diabetic retinopathy. Am $\mathcal{F} O$ phthalmol 1980; 90: 297-303.

3 McLeod D. Silicone oil injection during closed microsurgery for diabetic retinal detachment. Graefes Arch Clin Exp Ophthalmol 1986; 224: 55-9.

4 Yeo JH, Michels RG, Glaser BM. Silicone oil in the treatment of complicated retinal detachments. Ophthalmology 1987; 94: 1109-13.

5 Leaver PK, Grey RHB, Garner A. Silicone oil injection in the treatment of massive preretinal retraction. II. Late complications in 93 eyes. Brf Ophthalmol 1979; 63: 361-7.

6 Okun E. Intravitreal surgery utilising liquid silicone. Trans Pacific Coast Oto-ophthalmol Soc 1968; 49: 141-59.

7 Haut J. Ullern M, Chermet M, Van Effenterre G. Complications of intraocular injections of silicone combined with vitrectomy. Ophthalmologica 1980; 180: 29-35

$8 \mathrm{Kanski} \mathrm{JJ,} \mathrm{Daniel} \mathrm{R.} \mathrm{Intravitreal} \mathrm{silicone} \mathrm{injection} \mathrm{in} \mathrm{retinal}$ detachment. Br $\mathcal{F}$ Ophthalmol 1973; 57: 542-5.

9 Cockerham WD, Schepens CL, Freeman HM. Silicone injection in retinal detachment. Arch Ophthalmol 1970; 83: 704-12.

10 McLeod D, James CR. Visco-delamination at the vitreoretinal juncture in severe diabetic eye disease. $\mathrm{Br} \mathcal{F}$ Ophthalmol 1988; 72: 413-9. 
11 Gonvers M. Temporary use of intraocular silicone oil in the treatment of detachment with massive periretinal treatment of detachment with massive
proliferation. Ophthalmologica $1982 ; 184: 210-8$.

12 Leaver PK, Lean JS. Management of giant retinal tears using vitrectomy and silicone oil/fluid exchange: a preliminary vitrectomy and silicone oilffluid exchange: a prelimin
report. Trans Ophthalmol Soc UK 1981; 101: 189-91.

13 Casswell AG, Gregor ZJ. Silicone oil removal 1. The effect on: the complications of silicone oil. Br $\mathcal{F}$ Ophthalmol 1987; 71: 893-7.

14 Casswell AG. Gregor ZJ. Silicone oil removal 2. Operative and postoperative complications. $\mathrm{Br} F$ Ophthalmol 1987; 71 : 898-902.

15 McCuen BW II, de Juan E Jr, Landers MB III, Machemer R. Silicone oil in vitreoretinal surgery. 2. Results and complications. Retina 1985; 5: 198-205.
16 Zivojnovic R, Mertens DAE, Peperkamp E. Das flussige silikon in der amotiochirurgie. II. Bericht uber 280 falleweitere entwicklung der technik. Klin Monatsbl Augenheilkd 1982;181: 444-52.

17 Michels RG. Vitrectomy for complications of diabetic retinopathy. Arch Ophthalmol 1978; 96: 237-46.

18 Leaver PK, Cooling RJ, Feretis EB, Lean JS, McLeod D. Vitrectomy and fluid/silicone-oil exchange for giant retinal tears: results at six months. $\mathrm{Br} \mathcal{F}$ Ophthalmol 1984; 68: 432-8.

19 Charles S. Vitreous microsurgery. Baltimore: Williams \& Wilkins, 1981: 124.

20 Wilson-Holt N, Gregor Z. Spontaneous relieving retinotomies in diabetic silicone filled eyes. Eye 1992; 6: 1614. 